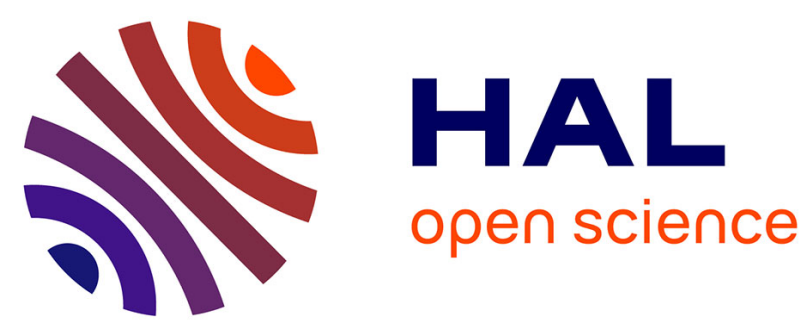

\title{
Novel system of communication in crickets originated at the same time as bat echolocation and includes male-male multimodal communication
}

Jose Luis Benavides-Lopez, Hannah ter Hofstede, Tony Robillard

\section{- To cite this version: \\ Jose Luis Benavides-Lopez, Hannah ter Hofstede, Tony Robillard. Novel system of communication in crickets originated at the same time as bat echolocation and includes male-male multimodal com- munication. The Science of Nature Naturwissenschaften, 2020, 107 (1), 10.1007/s00114-020-1666-1 . hal-02446809}

\author{
HAL Id: hal-02446809 \\ https://hal.science/hal-02446809
}

Submitted on 21 Jan 2020

HAL is a multi-disciplinary open access archive for the deposit and dissemination of scientific research documents, whether they are published or not. The documents may come from teaching and research institutions in France or abroad, or from public or private research centers.
L'archive ouverte pluridisciplinaire HAL, est destinée au dépôt et à la diffusion de documents scientifiques de niveau recherche, publiés ou non, émanant des établissements d'enseignement et de recherche français ou étrangers, des laboratoires publics ou privés. 
1 Novel system of communication in crickets originated at the same time as bat

2 echolocation and includes male-male multimodal communication

3

4 Jose Luis Benavides-Lopez1 (https://orcid.org/0000-0002-8715-1332)

5 Hannah ter Hofstede2,3,4 (https://orcid.org/0000-0002-7870-760X)

6 Tony Robillard1,4 (https://orcid.org/0000-0002-2177-9549)

7

$8{ }^{1}$ Institut de Systématique, Evolution et Biodiversité (ISYEB), Muséum national d'Histoire

9 naturelle, CNRS, Sorbonne Université, EPHE, Université des Antilles, 57 rue Cuvier, CP 50,

1075231 Paris Cedex 05, France

$11{ }^{2}$ Department of Biological Sciences, Dartmouth College, Hanover, New Hampshire 03755.

$12{ }^{3}$ Smithsonian Tropical Research Institute, Ancon, Panamá.

$13{ }^{4}$ Co-senior author

14

15

16

17 


\section{Abstract}

19 Understanding the evolutionary origins of communication signals requires careful study of

20 multiple species within a known phylogenetic framework. Most cricket species produce low-

21 frequency calls for mate attraction, whereas they startle to high-frequency sounds similar to

22 bat echolocation. Male crickets in the tribe Lebinthini produce high-frequency calls, to which

23 females reply with vibrational signals. This novel communication system likely evolved by

24 male sensory exploitation of acoustic startle to high-frequency sounds in females. This

25 behavior was previously described for the Lebinthini from Asia. Here we demonstrate that

26 this novel communication system is found in a Neotropical species, Ponca hebardi, and is

27 therefore likely shared by the whole tribe Lebinthini, dating the origin of this behavior to

28 coincide with the origin of echolocation in bats. Furthermore, we document male duets

29 involving both acoustic and vibratory signals not previously described in crickets, and we

30 tentatively interpret it as competitive masking between males.

31

32 Keywords: Orthoptera, Predation; High-frequency calls; Vibrational signals; Multimodal

33 duets 


\section{Introduction}

36 How and why new communication signals evolve are enduring questions in evolutionary

37 biology (Searcy and Nowicki 2005; Bradbury and Vehrencamp 2011). To understand the 38 evolutionary origins of a communication system, studies must test hypotheses with

39 experiments that integrate detailed observations of behavior across multiple species in a

40 phylogenetic framework (Shaw 1995). Evidence from diverse taxa has shown that new mate

41 advertisement signals can arise when novel signals tap into a pre-existing perceptual bias of 42 females (Ryan and Cummings 2013), a process referred to as sensory exploitation. In most

43 cases, males produce signals that are similar to environmental cues that attract females,

44 such as food or shelter (Fleishman 1992; Proctor 1992; Rodd et al. 2002; Christy et al.

45 2003). Mate attraction signals that resemble predator cues are rare, likely because typical

46 responses to predator cues involve freezing or fleeing and not movement towards the cue.

47 Interestingly, the two taxa in which sensory exploitation of predator cues for mating has been

48 documented are both insects in which males produce high-frequency sounds in the range of

49 bat echolocation calls (moths (Nakano et al. 2013); crickets (ter Hofstede et al. 2015)). A key

50 assumption of these studies is that the signal evolved after the evolution of echolocation in

51 bats. Here we compare new behavioral data with dating from previously published

52 phylogenies to support the hypothesis that the timing of high-frequency calls in the cricket

53 tribe Lebinthini coincided with the timing of the origin of echolocation in bats. Convergence in

54 timing would suggest a rapid change in communication at the same time as the emergence

55 of a new and dangerous predator.

56 Males of most cricket species in the family Gryllidae produce low-frequency $(3-8 \mathrm{kHz})$

57 calling songs as intraspecific communication signals for mate attraction (Bennet-Clark 1989).

58 Female crickets find males by following the sound signal (positive phonotaxis). Alternatively,

59 when crickets hear high-frequency sounds in the range typically produced by bats for

60 echolocation, they show stereotyped anti-predator behaviors, including negative phonotaxis

61 in flight (Wyttenbach et al. 1996) and acoustic startle responses (running or jerking the body)

62 when perched on a surface (ter Hofstede et al. 2015). It is unclear whether crickets benefit 
63 from the acoustic startle response on the ground or if it is just a byproduct of the in-flight

64 response to bat calls. A recent study (ter Hofstede et al. 2015) revealed that an alternative

65 communication system evolved in crickets of the Lebinthini tribe (Eneopterinae), involving

66 major changes in every component of the usual cricket system of communication: males

67 produce high-frequency signals $(10-28 \mathrm{kHz})$ (Robillard and Desutter-Grandcolas 2004a),

68 females lack phonotaxis and instead produce vibrational signals in response to male calls,

69 and males locate females via vibrotaxis. The vibrational signal produced by lebinthine

70 females in response to the male's high-frequency call is remarkably similar in latency and

71 structure to the vibrations produced by acoustic startle responses observed in closely related

72 crickets when they hear high-frequency sounds typical of bat calls (ter Hofstede et al. 2015).

73 Therefore, it is hypothesized that the lebinthine communication system evolved through male

74 sensory exploitation of the acoustic startle response to high-frequency sounds in females (ter

75 Hofstede et al. 2015). Lebinthine crickets no longer startle to high-frequency sounds, and

76 females only produce the vibrational signal in response to sound with the temporal pattern of

77 the conspecific male when they are receptive to mating, suggesting that this has evolved into

78 a true communication signal in these species (ter Hofstede et al. 2015).

79 The lebinthine communication system was previously described for three species of

80 different genera from Asia and islands from the Pacific region (Fig. 1). The second major

81 branch of the Lebinthini, however, is found in the Neotropics (Fig. 1) (Vicente et al. 2017), but

82 communication has not been studied in these species. If species in the neotropical clade

83 demonstrate the same acoustic-vibrational duet as seen in the Asian-Pacific species, it would

84 support the hypothesis that this novel communication system evolved in the ancestor of the

85 entire tribe. The tribe Lebinthini is estimated to have diverged $\sim 55$ million years ago (Ma)

86 (95\% highest posterior density: 44.43-69.53 Ma (Vicente et al. 2017)), which coincides with

87 the time estimated for the origin of an echolocating ancestor in bats $58 \mathrm{Ma}$ (Shi and

88 Rabosky 2015; Thiagavel et al. 2018). Here, we test whether the species Ponca hebardi

89 Robillard, 2005 from the Neotropical Lebinthini lineage (Fig. 1) demonstrates the alternative

90 acoustic-vibrational communication system found in species from the Asian-Pacific clade of 
91 the Lebinthini. We recorded the calling song of this species for the first time and used the

92 recorded calls for playback experiments to test the behavioral responses of both sexes.

94 Methods

\section{Study animals}

96 Ponca hebardi is a nocturnal eneopterine cricket species (Fig. 1) previously known by only

97 two type specimens collected in 1954 on Barro Colorado Island, Panama (Robillard and 98 Desutter-Grandcolas 2005). We collected juveniles in the same locality in March 2017 and 99 maintained them in the laboratory. Crickets were separated by sex before final moult and 100 were tested in playback experiments two to four weeks after final moult. All male call 101 recordings and playback tests were conducted in a room lined with sound-attenuating foam

102 at controlled temperature and humidity conditions (temperature: $23.5 \pm 1{ }^{\circ} \mathrm{C}$, humidity: $60 \pm$ $10315 \%$ ). Specimens were deposited in the Muséum national d'Histoire naturelle, Paris (MNHN104 EO-ENSIF4124-4127) and recorded .wav files were deposited in the sound library of MNHN 105 under accession numbers MNHN-SO-2019-87 to MNHN-SO-2019-90 106 (https://sonotheque.mnhn.fr/).

\section{Male recordings and acoustic analysis}

109 Call recordings were obtained from four males with a modified condenser microphone 110 (CM16, Avisoft Bioacoustics, Berlin, Germany) with a frequency range of 3-150 kHz $\pm 6 \mathrm{~dB}$ 111 (R. Specht, pers. comm.). Each male was put individually in a suspended textile net cage 112 overnight with the lights off and the microphone suspended $30 \mathrm{~cm}$ above the cage. Sound113 triggered recordings were made using Avisoft Recorder software version 2.97 (Specht 2008) 114 and an 8-Pro MOTU sound card at a sampling rate of $96 \mathrm{k}$-samples per second (16 bit). To 115 generate audio files with accurate power spectra, we applied a user-defined finite impulse 116 response (FIR) filter in Avisoft-SASLab Pro version 4.40 that corrected for the microphone 117 frequency response. Temporal and spectral song features were measured using the 118 automatic parameter measurements feature in Avisoft-SASLab Pro (FFT length 256, 
119 rectangle window, $50 \%$ overlap). We measured syllable duration, syllable period (time from

120 start of one syllable to start of next) and dominant frequency (frequency with maximum 121 energy, $\mathrm{kHz})$.

\section{Playback experiments}

124 The responses of female and male $P$. hebardi to male calls were tested within a dark arena 125 (1.54 m x $0.65 \mathrm{~m}$ ). Playback experiments were conducted using an UltraSoundGate Player $126216 \mathrm{H}$ with Avisoft recorder USGH software and Avisoft Ultrasonic Dynamic Speaker Vifa. We

127 selected five calls from one male recording with acoustic parameters similar to the mean 128 values of the four recorded males. These calls were broadcasted at an amplitude of $65 \mathrm{~dB}$ at 129 the cricket, matching the natural amplitude of the call at $80 \mathrm{~cm}$, measured with an 130 SVAN971/Svantek sonometer. Playback experiments were monitored using a SONY 131 Handycam HDR-HC3 video camera using the night-shot vision function.

132 Six unmated females were tested for behavioral responses to male calls. In a first set 133 of experiments, phonotactic response was assessed with free moving individuals in an 134 arena. The floor of the arena was covered by white filter paper that was changed after each 135 experiment to remove any odor cues left by previously tested individuals. We placed each 136 cricket in the middle of the arena, broadcasted male calls for 10 minutes and observed 137 whether the female walked towards the speaker (positive phonotaxis). In a second set of 138 experiments, females were placed on a foam base covered by a layer of filter paper and 139 covered by a nylon mesh cage. For two of the six females, a custom accelerometer was 140 placed underneath the filter paper to record vibrational signals. Using a microphone pointed 141 at the speaker and the accelerometer below the female, we simultaneously recorded the 142 male call playback and the female vibrational responses on two channels using Avisoft 143 Triggering Hard-disk Recorder. From these recordings, we measured the dominant 144 frequency $(\mathrm{kHz})$, duration $(\mathrm{ms})$, and time delay after the male call $(\mathrm{ms})$ of the female 145 vibrational signals using Avisoft-SASLab Pro. 
In a third set of experiments, two unmated males were tested for behavioral responses

147 to male calls. Males were placed in the middle of the arena and covered by a nylon mesh

148 cage. A microphone was pointed at the cricket to record both the calls of the focal cricket and

149 the playbacks from the speaker behind the male. Due to the microphone orientation, the

150 focal male's calls and the broadcasted calls differed in amplitude on the oscillogram. From

151 these recordings, we measured the dominant frequency $(\mathrm{kHz})$, duration $(\mathrm{ms})$ and time delay

152 after the playback (ms) of the male calls using Avisoft-SASLab Pro. Videos monitoring

153 playback experiments were analyzed frame by frame to document the timing of the vibration

154 behavior of the focal male.

\section{Results}

157 The call of $P$. hebardi consisted of a single syllable with a mean duration of $51.2 \pm 8.6 \mathrm{~ms}$ 158 (mean $\pm \mathrm{SD})$, syllable period of $4.6 \pm 2.2 \mathrm{~s}$ and a dominant frequency of $17.6 \pm 0.3 \mathrm{kHz}(\mathrm{N}=$ 1594 crickets, $\mathrm{n}=160$ calls). The dominant frequency corresponded to the third harmonic peak 160 (Fig. 2A-B). Calls were emitted in bouts of $8.9 \pm 4.2$ syllables, lasting $35.7 \pm 16.7 \mathrm{~s}$, with a bout period of $52.6 \pm 0.1 \mathrm{~s}$.

Playback experiments were conducted with six $P$. hebardi females, all of which were observed visually and video recorded, and two of which were recorded with an

164 accelerometer. Playback experiments revealed that female $P$. hebardi $(\mathrm{N}=6$ crickets $)$ 165 produced vibrational signals at a specific time interval after male calls and showed no 166 phonotactic activity (SI-Video_part1). The female vibrational signal ( $\mathrm{N}=2$ crickets, $\mathrm{n}=200$ 167 signals) occurred $327.8 \pm 14.6 \mathrm{~ms}$ after the male's call and had a duration of $169.8 \pm 5.8 \mathrm{~ms}$, 168 with a dominant frequency of $97.0 \pm 3.9 \mathrm{~Hz}$.

169 The playback experiments demonstrated that male $P$. hebardi $(\mathrm{N}=2$ crickets, $\mathrm{n}=177$ $170 \pm 4$ playbacks per cricket) also responded to calls of other males, both by alternating their 171 own call between playbacks and by producing vibrational signals similar to those 172 documented in females (SI-Video_part2). The mean delay between a male call and the male 173 vibrational signal was $351 \pm 509 \mathrm{~ms}(\mathrm{~N}=1$ cricket, $\mathrm{n}=59$ vibrational signals), but was 
174 relatively variable, ranging from 30 to $2,490 \mathrm{~ms}$. Male vibrational signals were the first replies

175 to call playbacks and were usually followed by a call after $2.1 \pm 0.6 \mathrm{~s}$ (Fig. 2).

177 Discussion

178 Our data show that the Neotropical lebinthine species $P$. hebardi exhibits the same

179 type of communication behavior as the lebinthine species of the Asian-Pacific clade. The call

180 of $P$. hebardi consists of a single syllable with a high dominant frequency corresponding to

181 the third harmonic peak (Fig. 2A-B). The frequency structure is similar to other Lebinthini

182 species, and the call particularly resembles that of the species Cardiodactylus muria (ter

183 Hofstede et al. 2015). Playback experiments revealed that female $P$. hebardi produce

184 vibrational signals at a specific time interval after male calls and show no phonotactic activity

185 (SI-Video_part1). The female vibrational signal occurs after the males's call with a similar

186 delay and dominant frequency as previously studied Lebinthini species (Table 1). Therefore,

187 this novel communication system consisting of high-frequency male acoustic signals and

188 female vibrational replies likely evolved in the ancestor of the Lebinthini tribe, representing a

189 key innovation leading to the evolutionary diversification of these crickets (Robillard and

190 Desutter-Grandcolas 2004b; ter Hofstede et al. 2015).

191 A fascinating and unexpected result of the playback experiments demonstrated that

192 male $P$. hebardi also respond to calls of other males, both by alternating their own call

193 between playbacks and by producing vibrational signals similar to those documented in

194 females. These male vibrational signals have not been looked for in previously studied

195 species. The mean delay between a male call and the male vibrational signal was similar to

196 the delay measured for female signals, but was much more variable compared to the delay

197 between male call and female vibrational signals. Interestingly, most of the male vibrational

198 signals ( 49 of $59,83 \%$ ) had shorter delays than the mean female delay, with five very long

199 delays generating the higher mean and much larger standard deviation for male than female

200 delays. 
202 and occur in response to male calls, we suggest that the male vibrational signal evolved to

203 mask female replies to a rival male's calls, thereby preventing rival males from detecting and

204 locating females. This disruptive male strategy of mimicking the female signal in response to 205 another male's signal has been documented in other vibrationally duetting insects (Tauber 206 2001; Bailey et al. 2006; Mazzoni et al. 2009a, b; Legendre et al. 2012; Polajnar et al. 2014). 207 The delay between male call and male vibration signal was usually shorter than the delay 208 measured in females, perhaps ensuring that the male signal reaches the rival male before 209 the female reply. However, males occasionally produced vibrational signals at very long 210 intervals after another male call, suggesting that spontaneous vibrational signaling might also 211 be part of this species' signaling repertoire. In addition, $P$. hebardi males produce their own 212 acoustic signal between acoustic signals of the rival male, allowing them to maintain a duet 213 with the female. This behavior has the potential to increase a male's mating success if the 214 male can produce a masking signal that increases the time required by the rival male to 215 reach the female (Bailey et al. 2006; Legendre et al. 2012; Cocroft et al. 2014) without 216 decreasing his own call production (Bailey et al. 2006; Legendre et al. 2012).

217 In crickets, male-male interactions such as aggressive songs, fighting, phonotaxis, and 218 victory displays are all known in behavioral contexts linked to male rivalry (Shaw et al. 1990; 219 Brown et al. 2006; Bertram et al. 2010; McCarthy et al. 2013). Nevertheless, those 220 interactions almost exclusively rely on acoustic signals occurring at long range, or consist of 221 multimodal short-range aggressive behaviors. The novel long-range male-male bimodal 222 interactions described here significantly increase the behavioral repertoire of cricket male223 male communication and adds to the complexity of the communication system of the 224 Lebinthini. Under the hypothesis that the Lebinthini's communication system evolved by 225 sensory exploitation of a startle response in females, it is likely that male vibrational signals 226 originated through a similar mechanism, by tapping into preexisting sensory biases both in 227 male and female receivers (ter Hofstede et al. 2015). These interactions suggest selection 228 pressure in the form of competition among males for detecting female responses and 
229 contending with eavesdropping rival males (Bailey 1991; Mc Gregor 2005; Cocroft et al. 230 2014).

231 This study supports an origin of the acoustic-vibratory duet in the ancestor of both the

232 Paleo- and Neotropical Lebinthini clades and demonstrates a potential novel male strategy

233 for thwarting rival males while communicating with a female. Both vibrational and acoustic

234 communication are common and widespread in insects and arthropods (Cocroft et al. 2014),

235 but only a handful of species are known to use bimodal acoustic-vibrational signals in 236 reciprocal interactions between and among sexes (Rajaraman et al. 2015; ter Hofstede et al.

237 2015). Understanding how these communication systems function can help us understand 238 conditions that favor multimodal communication and competitive interactions within these 239 systems. The presence of the novel acoustic-vibrational duet in the Neotropical lineage of the

240 Lebinthini supports the hypothesis that it evolved in the ancestor of this tribe and provides a 241 time estimate of $\sim 55 \mathrm{Ma}$ for the origin of this novel communication system. This coincides 242 remarkably well with the estimated time for the origin of echolocation in bats $(\sim 58 \mathrm{Ma})$, 243 suggesting a potentially rapid adaptation to a new predator and subsequent effects on 244 communication within crickets. As methods for molecular dating improve, more accurate 245 estimates will reveal how closely these events occurred in time and provide answers about 246 the rate of evolutionary change in a novel communication system.

248 List of supplementary information

249 Excel file with datasets: DATA_Ponca.xlsx

250 SI-Video: Video file of female (Part 1) and male (Part 2) responses to acoustic playback.

\section{Authors' contributions}

253 TR collected the specimens. J.L.B.-L. conducted behavioral recording experiments. All 254 authors contributed to the conception, design, analysis and writing.

\section{Competing interests}


We have no competing interests.

\section{Funding}

260 The study was realized as part of the PhD project of JLBL, funded by Colciencias scholarship 261 (756-2016). Field work in Panama was possible thanks to a grant from Action Transversal du 262 Museum (MNHN).

\section{Acknowledgements}

We thank the Smithsonian Tropical Research Institute staff for logistical assistance during field collections on Barro Colorado Island (Panamá). Specimens were collected under scientific permit No.SEX/A-27-17 from the Ministerio de Ambiente de Panama. We thank

268 Stefan Schöneich for advice and Marion Guillaume for cricket maintenance assistance in 269 MNHN.

Ethical approval: All applicable international, national, and/or institutional guidelines for the care and use of animals were followed.

\section{References}

275 Bailey W, Macleay C, Gordon T (2006) Acoustic mimicry and disruptive alternative calling

Bailey WJ (1991) Acoustic Behaviour of Insects. An evolutionary perspective. Chapman and Hall, London

Bennet-Clark HC (1989) Songs and the physics of sound production. In: Huber F, Moore TE, Loher W (eds) Cricket behavior and neurobiology. Comstock Publishing Associates, $283 \quad$ Ithaca and London, pp 227-261

284 Bertram SM, Rook VLM, Fitzsimmons LP (2010) Strutting their stuff: Victory displays in the 
spring field cricket, Gryllus veletis. Behaviour 147:1249-1266.

Bradbury JW, Vehrencamp SL (2011) Principles of animal communication, Second edition.

Brown WD, Smith AT, Moskalik B, Gabriel J (2006) Aggressive contests in house crickets: size, motivation and the information content of aggressive songs. Anim Behav 72:225233 https://doi:10.1016/j.anbehav.2006.01.012

Christy JH, Schober U, Backwell PRY (2003) Interspecific attractiveness of structures built by

Cocroft R B, Gogala M, Hill PS, \& Wessel A (Eds). (2014). Studying vibrational communication (Vol. 3). Berlin: Springer.Fleishman LJ (1992) The influence of the

McCarthy TM, Keyes J, Cade WH (2013) Phonotactic Behavior of Male Field Crickets

311 (Gryllus texensis) in Response to Acoustic Calls From Conspecific Males. J Insect 
313 Nakano R, Takanashi T, Surlykke A, et al (2013) Evolution of deceptive and true courtship

314 songs in moths. Sci Rep 3.. https://doi.org/10.1038/srep02003

315 Polajnar J, Eriksson A, Valerio M, et al (2014) The process of pair formation mediated by

316 substrate-borne vibrations in a small insect. Behav Processes 107:68-78.

317 https://doi.org/10.1016/j.beproc.2014.07.013

318 Proctor HC (1992) Sensory exploitation and the evolution of male mating behaviour: a

319 cladistic test using water mites (Acari: Parasitengona). Anim Behav 44:745-752

$320 \quad$ https://doi.org/10.1016/S0003-3472(05)80300-8

321 Rajaraman K, Godthi V, Pratap R, Balakrishnan R (2015) A novel acoustic-vibratory

322 multimodal duet. J Exp Biol 218:3042-3050. https://doi.org/10.1242/jeb.122911

323 Robillard T, Desutter-Grandcolas L (2004a) High-frequency calling in Eneopterinae crickets

324 (Orthoptera, Grylloidea, Eneopteridae): Adaptive radiation revealed by phylogenetic analysis. Biol J Linn Soc 83:577-584. https://doi.org/10.1111/j.1095-8312.2004.00417.x

Robillard T, Desutter-Grandcolas L (2005) A revision of Neotropical crickets (Orthoptera, Grylloidea, Eneopteridae). Insect Syst Evol 411-435 https://doi:10.1163/187631204788912427

Robillard T, Desutter-Grandcolas L (2004b) Evolution of acoustic communication in crickets:

Rodd FH, Hughes KA, Grether GF, Baril CT (2002) A possible non-sexual origin of mate preference: Are male guppies mimicking fruit? Proc R Soc B Biol Sci 269:475-481. https://doi.org/10.1098/rspb.2001.1891

Ryan MJ, Cummings ME (2013) Perceptual Biases and Mate Choice. Annu Rev Ecol Evol Syst 44:437-459. https://doi.org/10.1146/annurev-ecolsys-110512-135901

Searcy WA, Nowicki S (2005) The evolution of animal communication: reliability and deception in signaling systems. Princeton University Press, Princeton NJ

Shaw KC, Galliart PL, Smith B (1990) Acoustic Behavior of Amblycorypha parvipennis ( 
343 Shaw KL (1995) Phylogenetic tests of the sensory exploitation model of sexual selection. Trends Ecol Evol 10:117-120 https://doi.org/10.1016/s0169-5347(00)89005-9

Shi JJ, Rabosky DL (2015) Speciation dynamics during the global radiation of extant bats. Evolution (N Y) 69:1528-1545. https://doi.org/10.1111/evo.12681

347 Specht R (2008) Avisoft-SASlab Pro: Sound Analysis and Synthesis Laboratory, Berlin

348 Sueur J, Aubin T, Simonis C (2008) Seewave: a free modular tool for sound analysis and synthesis. Bioacoustics 18:213-226 https://doi.org/10.1080/09524622.2008.9753600

350 Tauber E (2001) Bidirectional communication system in katydids: the effect on chorus structure. Behav Ecol 12:308-312. https://doi.org/10.1093/beheco/12.3.308

352 ter Hofstede HM, Schöneich S, Robillard T, et al (2015) Evolution of a Communication

353 System by Sensory Exploitation of Startle Behavior. Curr Biol 25:3245-3252. https://doi.org/10.1016/j.cub.2015.10.064

Thiagavel J, Cechetto C, Santana SE, et al (2018) Auditory opportunity and visual constraint enabled the evolution of echolocation in bats. Nat Commun 9:. https://doi.org/10.1038/s41467-017-02532-x

358 Vicente N, Kergoat GJGJ, Dong J, et al (2017) In and out of the Neotropics: historical biogeography of Eneopterinae crickets. J Biogeogr 44:2199-2210.

$360 \quad$ https://doi.org/10.1111/jbi.13026

361 Wyttenbach RA, May ML, Hoy RR (1996) Categorical perception of sound frequency by 
365 Table 1: Male and female communication signal features for previously studied Asian-Pacific

366 lebinthine species and the Neotropical species Ponca hebardi. Values are means \pm standard

367 deviations. Sample sizes are reported in brackets (number of crickets; number of vibrational

368 signals). Values for A. obscurus, C. muria and L. luae from ter Hofstede et al. (2015).

\begin{tabular}{lcccc}
\hline Species & $\begin{array}{c}\text { Male } \\
\text { dominant } \\
\text { frequency } \\
(\mathrm{kHz})\end{array}$ & $\begin{array}{c}\text { Female vibration } \\
\text { frequency } \\
(\mathrm{Hz})\end{array}$ & $\begin{array}{c}\text { Female vibration } \\
\text { delay } \\
(\mathrm{ms})\end{array}$ & $\begin{array}{c}\text { Male vibration } \\
\text { delay } \\
(\mathrm{ms})\end{array}$ \\
\hline A. obscurus & 15 & $48 \pm 5(8 ; 42)$ & $141 \pm 8(7 ; 7)$ & $?$ \\
C. muria & 14 & $38 \pm 3(9 ; 88)$ & $631 \pm 43(10 ; 10)$ & $?$ \\
L. luae & 17 & $84 \pm 4(9 ; 76)$ & $138 \pm 8(9 ; 9)$ & $?$ \\
P. hebardi & 17 & $97 \pm 3(2 ; 200)$ & $327 \pm 14(2 ; 200)$ & $351 \pm 509(1 ; 59)$ \\
\hline
\end{tabular}

370

371 
372 Fig. 1 Evolutionary relationships within the cricket tribe Lebinthini. (a) Phylogenetic tree of

373 the Lebinthini inferred through Bayesian and maximum likelihood approaches based on four

374 mitochondrial and three nuclear gene sequences (modified from Vicente et al. (2017), with

375 arrows pointing to the phylogenetic positions of Ponca hebardi and the Asian-Pacific

376 lebinthine species previously analyzed by (ter Hofstede et al. 2015). (b) photo of male $P$.

377 hebardi on vegetation

378

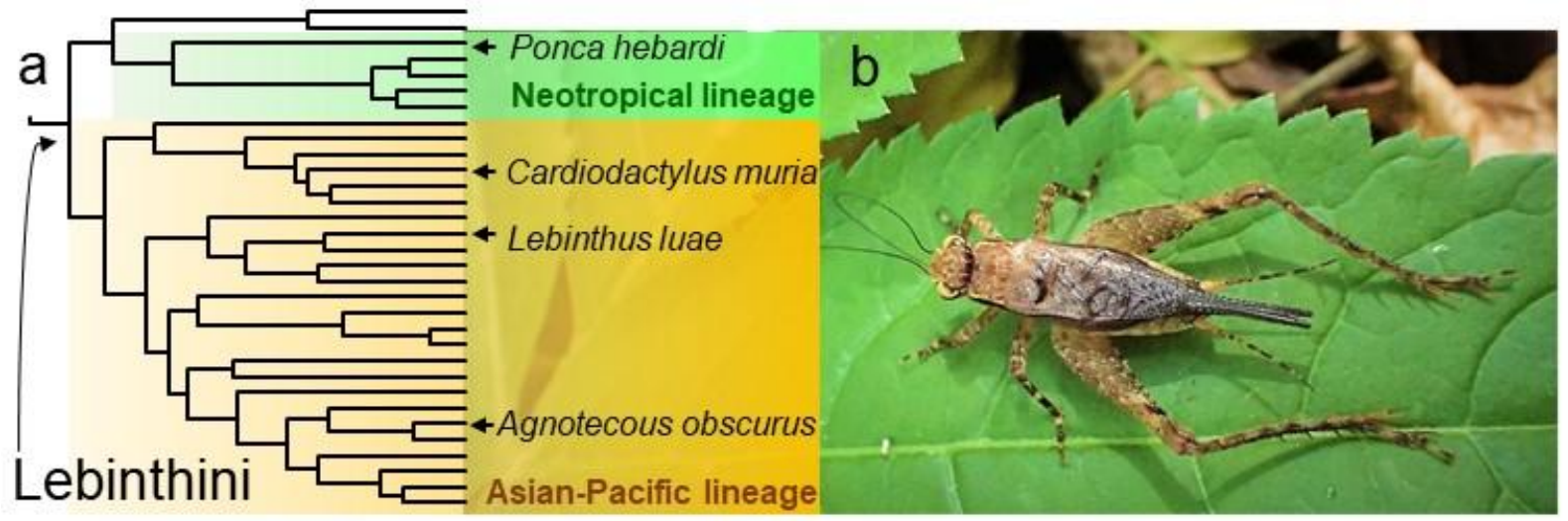


380 Fig. 2 Communication signals of the species Ponca hebardi. (a, b) Spectrograms (top trace)

381 and oscillograms (bottom trace) of the calling song of $P$. hebardi: (a) three syllables over 8

382 seconds; (b) detailed view of one syllable. (c) Example of accelerometer recording of a

383 female vibrational reply (upper trace) to the male call (lower trace). The male call is clipped in

384 this recording due to the high gain needed to get a suitable signal-to-noise ratio for the

385 vibrational signal recording, but the call itself was not distorted during playback. Graphs

386 made with the R package 'seewave' (Sueur et al. 2008)

a

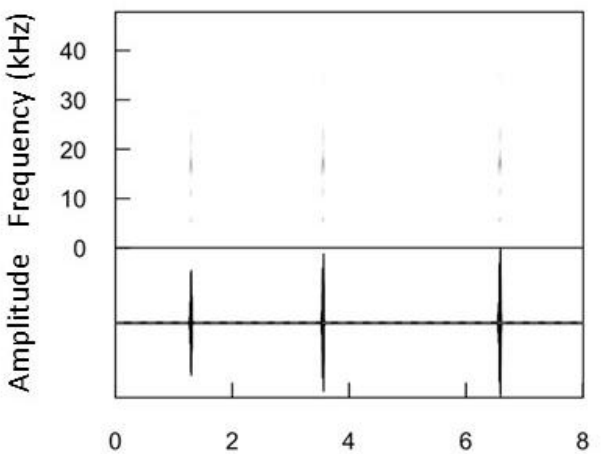

b

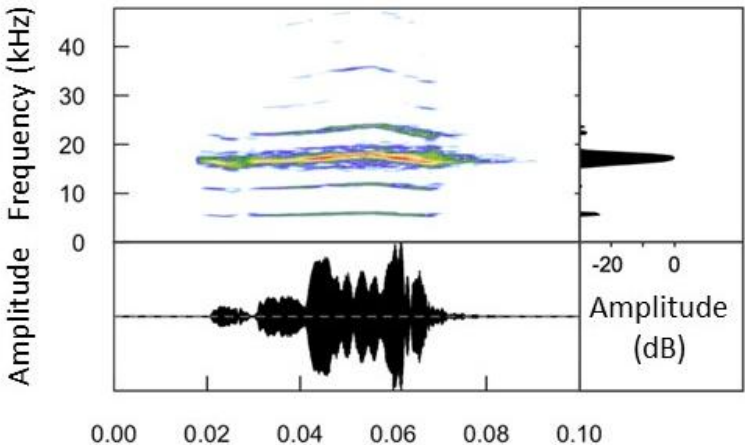

C

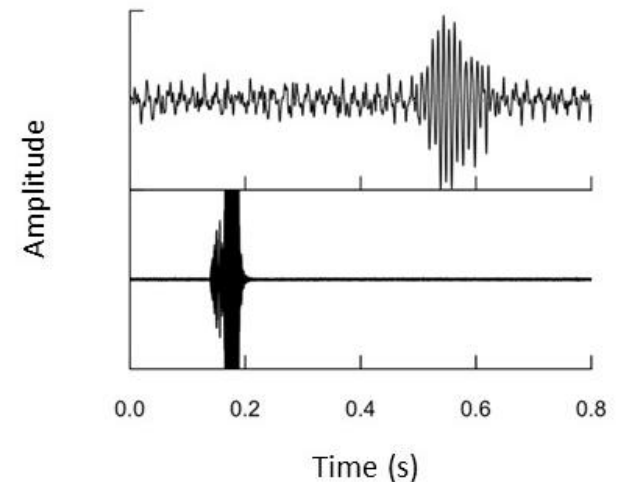

Time (s) 
390 Fig. 3 Results of playback experiments with the species Ponca hebardi. (a) Behavioral

391 responses of $P$. hebardi females to a speaker broadcasting conspecific male calling song. (b)

392 Delay between the male call and the female $(n=200)$ and male $(n=56)$ vibrational reply 393
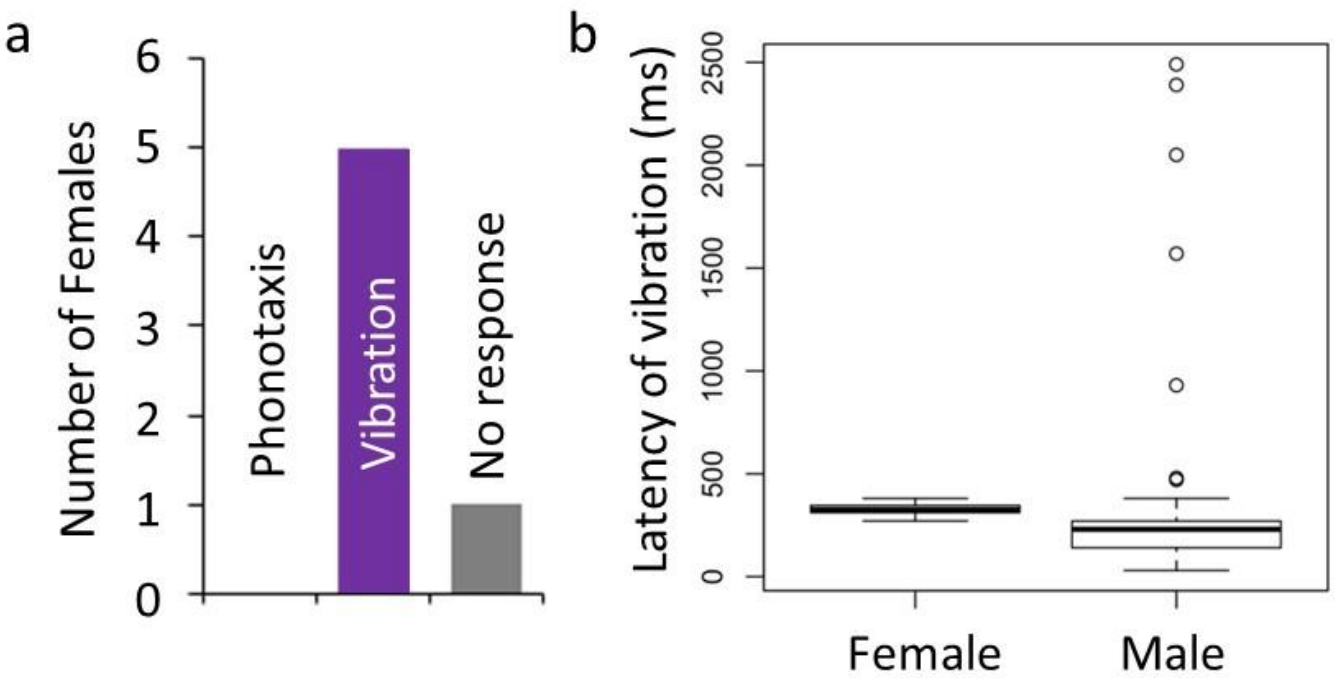

394 